\title{
Research on the Development of Automotive Industry
}

\author{
Shanshan Zhong ${ }^{a}$, Guoping Cheng ${ }^{\text {b }}$ \\ School of Management, Wuhan University of Technology, Wuhan 430070, China \\ a936756541@qq.com, bGuopingcheng@tom.com
}

Keywords: automobile, transportation, GDP, consumer.

\begin{abstract}
Since the policy of reform and opening up, China's economic has take-off rapidly. All walks of life has been flourishing, where the automotive industry was particularly notable. Car has changed from luxury goods to a necessity of life. Automotive industry chain is very long, involving a variety of industries, so the development of the automotive industry plays an important role in promoting China's economic. In this paper, I think the healthy development of the automotive industry involves three aspects. Firstly, the products should meet the needs of consumers. Secondly, consumers have the ability to buy. Thirdly, supporting the construction of appropriate facilities. I hope this paper can guide the development of the automotive industry.
\end{abstract}

\section{Introduction}

The automotive industry is a high input and high output industry,involving a very long industry chain.It has become an important pillar of China's economic development.The upstream industry chain of automobile industries includes steel, rubber, machinery, glass, nonferrous metals, etc.The downstream industry chain, includes maintenance, insurance claims, logistics, road construction, and so on.In addition, there are automobile after markets, including the supply of auto parts, hairdressing for cars, traveling with cars, motels and gas stations. The development of the automotive industry can promote the development of petroleum, steel, rubber, chemical and other related industries.

All in all, In the case of the current per capita consumption of cars is much lower than the level of foreign cars, and should vigorously promote the development of the automotive industry.

\section{The healthy development of the automotive industry involves three aspects.}

The products should meet the needs of consumers. Any products only meet consumer demand, can they have the market. While,there is a gap between goods or services provided by enterprises and what the consumers expecting to get.We call it the demand gap.How to make products meet consumer demand? We can refer to the Service Quality Gap Model.Service quality gap model is proposed by well-known scholars Berry and Parasuraman in 1985, the model reveals the process and why of a demand gap.

From the service quality gap model, it can be seen: the consumer has his own standards of service before his consumption. The next is the enterprises perception of customer's standards of service expectations.Due to the inaccurate interpretation of standards or managers know gap and other reasons, results in the appearance of gap one. Then is the service marketing design activities.Due to the work ability and a variety of subjective and objective factors, standards and services designed by enterprises don't match the consumer expectations, which led to the emergence of gap two. Next is the service delivery process.Due to the inevitable gap between behavior and standards, hence there is the gap three. There is a gap between service delivery and communication between enterprises and customers, leading to the gap four. In fact, throughout the consumption process, every step may have gaps.If we use mathematical expressions to represent the relationship between the demand gap and the four gaps.I think it should be:

Demand gap $\geqq$ gap one+gap two+gap three+gap four 


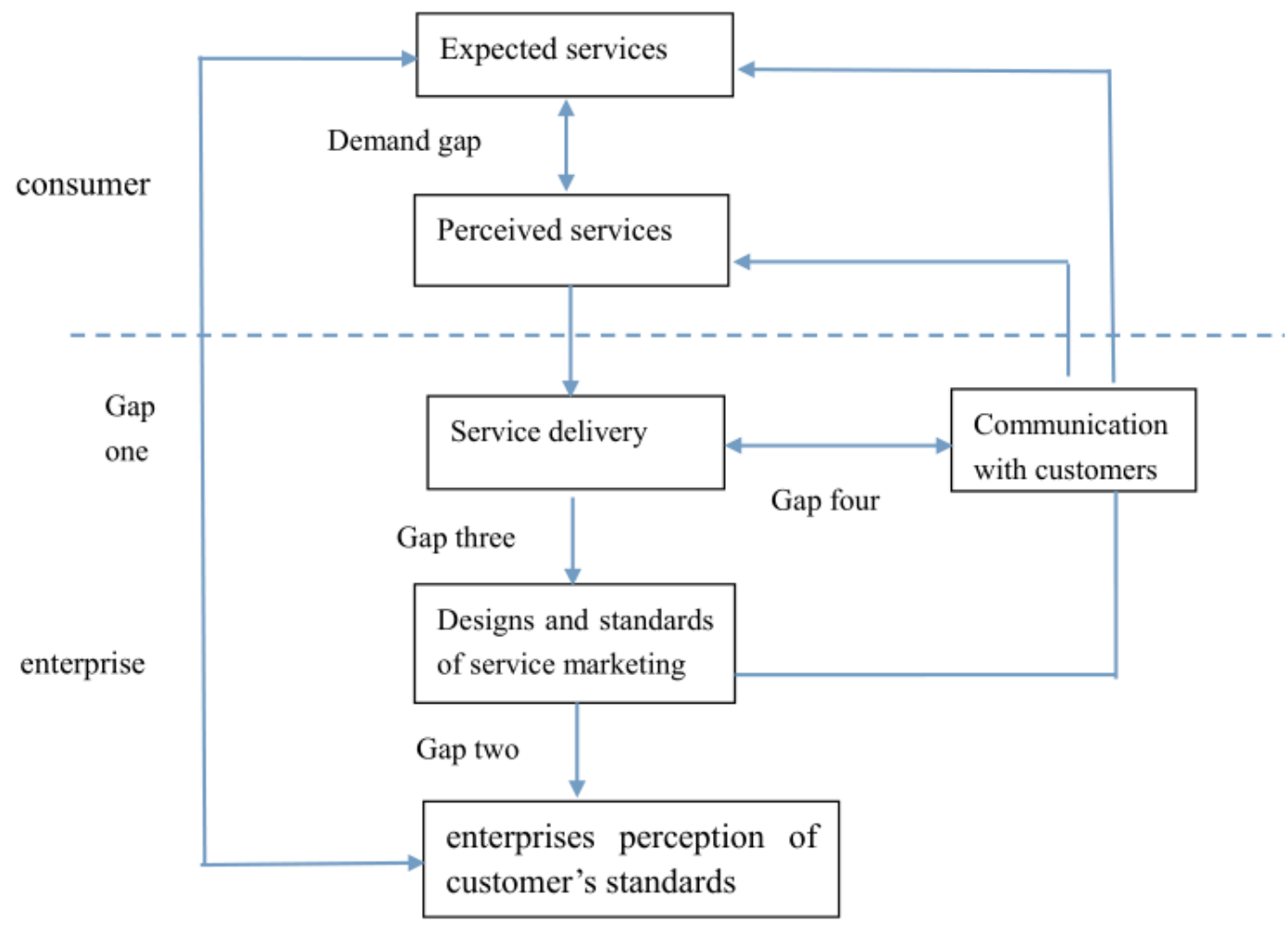

Fig. 1 Service quality gap model

Quality service model helps us understand the formation of the demand gap well. Therefore, enterprises should pay attention to every aspect of marketing.Companies should improve communication skills of the marketing staff and increase research and development. Besides, companies should also improve technology and the quality of service, trying to minimize the demand gap.

Consumers have the ability to buy.Purchasing power of consumers not only in relation to the economic development but also in relation to the income level of people. Besides, companies should also reduce costs and lower prices.

Automotive industry and economic development influence each other. Undoubtedly, the development of the automotive industry will promote the development of economy. In turn, economic development can lead to increased spending power of the people, so that it will promote the development of the automotive industry, forming a virtuous circle. The following table is the statistics of China's GDP and private car ownership for the past decade.

Table 1 Statistics of China's GDP and private car ownership

\begin{tabular}{c|c|c|c|c|c}
\hline Year & 2004 & 2005 & 2006 & 2007 & 2008 \\
\hline GDP (billion) & $15,987.834$ & $18,493.737$ & $21,631.443$ & $26,581.031$ & $31,404.543$ \\
\hline $\begin{array}{c}\text { Number of } \\
\text { private cars(thousand) }\end{array}$ & $14,816.6$ & $18,480.7$ & $23,333.2$ & $28,762.2$ & $35,013.9$ \\
\hline \multicolumn{7}{|c|}{} & & & & 2012 & 2013 \\
\hline Year & 2009 & 2010 & $47,310.405$ & $51,947.01$ & $56,884.521$ \\
\hline GDP (billion) & $34,090.281$ & $40,151.28$ & & 88,386 & $105,016.8$ \\
\hline
\end{tabular}

Using SPSS19.0 software do the correlation analysis and the results in the table below: 
Table 2 The results of correlation analysis

\begin{tabular}{|c|c|c|c|}
\hline \multicolumn{2}{|c|}{ Correlations } & \multicolumn{2}{c|}{$\begin{array}{c}\text { Number of } \\
\text { private cars }\end{array}$} \\
\hline \multirow{2}{*}{$\begin{array}{c}\text { Number of } \\
\text { private } \\
\text { cars }\end{array}$} & Pearson Correlation & 1 & $.989^{* *}$ \\
\cline { 2 - 4 } & Sig. (2-tailed) & 10 & .000 \\
\hline \multirow{2}{*}{ GDP } & $\mathrm{N}$ & $.989^{* *}$ & 10 \\
\hline & Pearson Correlation & .000 & 1 \\
\cline { 2 - 4 } & Sig. (2-tailed) & 10 & 10 \\
\cline { 2 - 4 } & $\mathrm{N}$ & & \\
\hline
\end{tabular}

The above table shows that: over the past decade, the number of private cars and GDP showed a highly positive correlation coefficient of 0.989 . Therefore, in order to improve the purchasing power of consumers, the government should vigorously develop the economy and improve people's income level.

Companies should establish a scientific cost management system. Companies can reduce cost by technological innovation, improvement of equipment utilization and good relations with suppliers.By doing this, companies can reduce product prices, so that increase consumer purchasing power.

Supporting the construction of appropriate facilities. Healthy development of the automotive industry also depends on the construction of supporting facilities. Such as the length and quality of highway, number and location of gas stations, which are important factors affecting the development of the automotive industry. Road construction is the most important and the most basic condition for the development of the automotive industry.Road quality and length directly affect the traffic conditions of a region.Improvement of traffic conditions is not only conducive to the flow and reasonable configuration of resources, but also conducive to the movement of persons.Besides, it can in favor of contacting with the outside world, so that it can develop the regional economy.Then people have the spending power to buy a car, and they can use the car under the good quality of road.So, good roads, transportation line is both a prerequisite and one of its major facilities for the development of the automotive industry.

Secondly, the building, site selection and distribution of gas station should be reasonable.Gas stations should be built in the place with more traffic to facilitate the consumers.At the same time,we should take the surrounding gas station coverage into account, as well as environmental and safety problems.

Finally, automotive repair service, car hairdressing and 4S shop, all these things must serve for consumers. They should improve service quality so as to promote the healthy development of the automotive industry.

\section{Conclusion}

In summary, the development of the automotive industry should note the following:

First, pay attention to the product quality and functionality.Communicate with consumers and try to understand what they want.Companies should strive to meet consumer demand, even the potential demand.

Second, the government should take measures to vigorously develop the economy and make people rich. Enterprises should improve their technology and improve equipment. Besides, they should maintain good relations with suppliers to reduce costs. 
Third, the government and enterprises should complete the supporting facilities construction, which is a strong guarantee of the automotive industry development.

The development of the automotive industry has a far-reaching effect on China's economic construction.Our country should vigorously promote the development of the automotive industry. In order to develop sustainably, the automotive industry needs to produce products that meet consumer needs and the government should develop the economy, improve the purchasing power of consumers and improve the infrastructure.

\section{References}

[1] Zhou yi. The research On value marketing strategy Of ALV China auto parts company[D]. Shanghai: Huadong University of technology. P8.

[2] Information on http://www.stats.gov.cn.

[3] 2013 Yearbook of China's auto market [M].China Commercial Press.2013.220-221. 